\title{
OBSTRUCTIVE HYDROCEPHALUS IN CHILDHOOD
}

\author{
BY \\ D. S. GORDON and A. R. TAYLOR \\ From the Department of Neurological Surgery, Royal Victoria Hospital, Belfast
}

(RECEIVED FOR PUBLICATION JANUARY 23, 1956)

The differential diagnosis of obstructive hydrocephalus in childhood involves a consideration of two main groups of cases, cerebellar tumours and obstructive lesions of a non-neoplastic nature. The most common of the non-neoplastic conditions are stenosis of the aqueduct of Silvius and obliteration of the outlet of the fourth ventricle.

In the literature on obstructive hydrocephalus the radiological distinctions between the neoplastic and the non-neoplastic groups have been well drawn mainly by improved techniques in ventriculography. The pathological aspects have been described by Russell (1949), but their differentiation by clinical methods has not received as much attention. The distinction is important as the hydrocephalus in the non-neoplastic cases can usually be relieved.

Many cases of stenosis of the aqueduct and occlusion of the outlet of the fourth ventricle are initially diagnosed as cerebellar tumours. This review was carried out with the object of establishing a means of reaching the diagnosis by clinical methods with the aid of a plain radiograph of the skull.

\section{Material}

Twenty-three cases were studied, 15 with cerebellar tumours and eight with non-neoplastic obstructions; of the latter four were stenoses of the aqueduct and four occlusion of the foramina of the fourth ventricle. The ages in the two groups were comparable, varying from 3 to 15 years.

The tumours were either medulloblastomas or astrocytomas, the obstructions in the fourth ventricle were all caused by arachnoid adhesions, the type produced by congenital atresia not being represented. The aetiology in the aqueduct stenosis group is not known but is usually a subependymal gliosis of uncertain origin.

\section{Symptomatology}

The length of the history is not always an accurate guide to the chronicity of the lesion. It might be supposed that in a chronic obstruction of the cerebrospinal fluid pathways the history would be longer than that of a rapidly growing tumour. However, five of the eight cases in the non-neoplastic group presented with symptoms of less than six months and the longest history was of two years' duration. The history in medulloblastoma was less than six months in all cases and in astrocytoma of the cerebellar hemispheres from three to 18 months.

The sudden onset and short duration of symptoms in aqueduct stenosis and fourth ventricular obstruction is often misleading. According to Lazorthes (1954) equilibrium can be maintained for many years. Decompensation may follow intercurrent illness, ventricular puncture or progression of the causal lesion quickly producing the familiar signs of intracranial hypertension.

In medulloblastoma the midline cerebellar syndrome of vomiting with or without headache and gross bilateral ataxia, mainly of the legs, was the typical history in most cases.

Astrocytomas being usually situated in one cerebellar hemisphere, there was often a history of staggering to one side and other evidence of unilateral cerebellar ataxia in addition to headache and vomiting.

Some features were peculiar to the history of the non-neoplastic group. Mental backwardness noticed by parents or teachers was quite marked in three of the eight cases. Putnam (1934) emphasized that a poor pre-operative mental state is associated with a higher operative mortality and a worse prognosis generally. Three children were brought to their doctors on account of increasing obesity, the symptoms of increased intracranial pressure, appearing some months later. This is due to hypothalamo-hypophyseal dysfunction, the pathogenesis of which will be referred to later. One other child had bouts of hypersomnolence. Russell (1949) has pointed out that these hypothalamic disturbances are an uncommon accompaniment of hydrocephalus so that the high incidence in this group is significant. 
Writing of stenosis of the aqueduct, Pennybacker (1940) described a peculiar coarse tremor which is exaggerated during purposeful movements. This was seen in two of the present series and was the initial symptom in one. Deterioration of vision was a symptom in two cases, and incontinence of urine was an early symptom in one.

In one child a past history of meningitis pointed to the diagnosis of adhesions at the outlet foramina of the fourth ventricle.

\section{Clinical Signs \\ An enlarged, globular head was sometimes a} striking feature in the non-neoplastic group. However, in other cases the circumference was no greater than in the tumour cases. Robinson (1953) remarks that in older children the cerebral ventricles may be very greatly enlarged and yet the head circumference be increased by only one to two inches.

The general condition of the child is important; children with medulloblastoma usually look ill and have lost weight, whereas many of the more chronic non-neoplastic obstructions are found in plump children, sometimes pathologically obese. Papilloedema was seen in practically every case in each group; one case of aqueduct stenosis had secondary optic atrophy with visual failure. Nystagmus, present in most of the tumour cases, was not found in the non-neoplastic group. It was surprising how few cerebellar signs were produced by the greatly dilated fourth ventricle in cases with obliteration of the outlet foramina.

There was marked unsteadiness of gait in cases of medulloblastoma. The remaining cases in each group showed lesser degrees of impairment. Incoordination of the limbs was seldom seen in the nonneoplastic cases and never lateralized; it was the rule in tumour cases and often lateralized.

\section{Radiology}

The plain radiograph of the skull showed some striking differences between the two groups.

In the infant the effects of raised intracranial pressure are increased convolutional markings and widening of the sutures with enlargement of the skull. Sutural expansion occurs readily in the infant so that papilloedema is not a feature of hydrocephalus at this age. In childhood expansion occurs less readily and after nine years further evidence of raised intracranial pressure may be seen consisting of decalcification and erosion of the posterior clinoid processes. In the younger child these structures are protected from pressure by sutural expansion.

When the raised intracranial pressure is due to

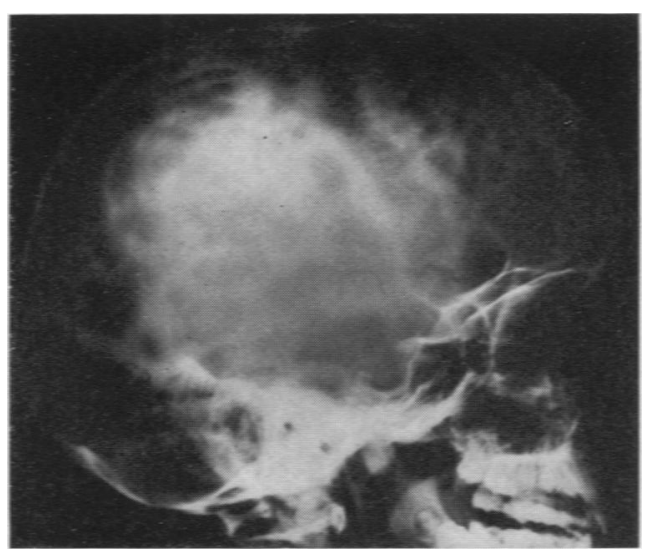

FG. 1.-Straight radiograph of the skull in a child aged 11 years with aqueduct stenosis showing increased convolutional markings, widened suture lines and enlargement of the pituitary fossa.

obstructive hydrocephalus the pituitary fossa may expand (Fig. 1). As pointed out by Bull (1953), this enlargement is rare under 10 years of age. Twining (1939a) has shown that the pituitary fossa enlargement is due to the pressure of a dilated third ventricle (Fig. 2) and is found in the more chronic cases of obstructive hydrocephalus. The dilated third ventricle and expanded pituitary fossa were features in those cases of chronic hydrocephalus presenting with evidence of hypothalamo-hypophyseal dysfunction.

Davidoff and Epstein (1950) conclude that astrocytoma of the cerebellum produces more marked radiological change than medulloblastoma, but quote only one tumour case with any sellar change. In arachnoiditis of the posterior fossa, five of their 10 cases had enlargement of the sella

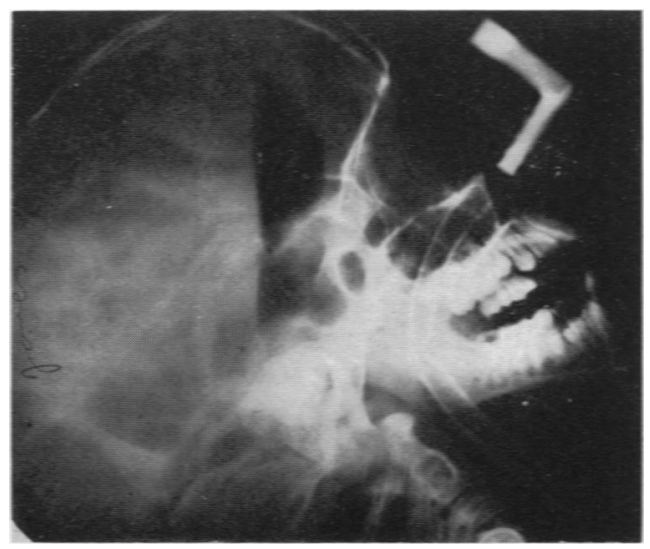

Fig. 2.-Ventriculogram from a child aged 10 years with aqueduct stenosis. The dilated third ventricle can be seen expanding the pituitary fossa. 
while in aqueduct stenosis only two out of $13 \mathrm{had}$ a normal sella.

In the present series all cases in the non-neoplastic group over 10 years showed erosion of the posterior clinoids and expansion of the pituitary fossa, whereas neither change was seen in any of the tumour cases. Presumably this is due to the rapid progress of medulloblastoma and to the fact that the astrocytoma, situated usually in one of the cerebellar hemispheres, obstructs the cerebrospinal fluid pathways at a relatively late stage in its evolution.

The main features of the conditions so far discussed are summarized in the Table.

TABLE

FEATURES OF NEOPLASTIC AND NON-NEOPLASTIC GROUPS

\begin{tabular}{|c|c|c|}
\hline Medulloblastoma & Astrocytoma & $\begin{array}{l}\text { Non-neoplastic } \\
\text { Group }\end{array}$ \\
\hline Short history & Longer history & Varying length of \\
\hline Ill appearance & $\begin{array}{l}\text { Usually good con- } \\
\text { dition }\end{array}$ & $\begin{array}{l}\text { Head often enlarged, } \\
\text { may be obese, often } \\
\text { mentally retarded, } \\
\text { may have visual } \\
\text { failure and coarse } \\
\text { tremor }\end{array}$ \\
\hline Gross bilateral ataxia & $\begin{array}{l}\text { Often unilateral cere- } \\
\text { bellar signs }\end{array}$ & Few cerebellar signs \\
\hline $\begin{array}{l}\text { Relatively slight } \\
\text { changes in the } \\
\text { plain radiographs }\end{array}$ & $\begin{array}{l}\text { May have more } \\
\text { chronic radio- } \\
\text { logical changes }\end{array}$ & $\begin{array}{l}\text { Radiological changes } \\
\text { of chronic obstruc- } \\
\text { tive hydrocephalus }\end{array}$ \\
\hline
\end{tabular}

Some other less common conditions in the differential diagnosis may be considered. Midbrain gliomata are uncommonly associated with chronic hydrocephalus. They are characterized by lesions of cranial nerves, cerebellar, sensory and pyramidal pathways.

In so-called otitic hydrocephalus a history of preceding febrile illness or aural disease may be obtained. There is bilateral papilloedema with an absence of any other neurological signs except for an occasional sixth nerve lesion. The general condition in these children is usually very good.

Suprasellar cysts show calcification in the plain radiograph in about $75 \%$ of cases. Ventriculography is sometimes necessary for their diagnosis.

In the Arnold-Chiari malformation there is always evidence of congenital spinal deformity, either an overt meningocoele or meningomyelocoele or spina bifida occulta. Platybasia can be diagnosed from a plain radiograph of the skull. Ventriculography is essential in confirming the diagnosis before surgery.

In stenosis of the aqueduct the funnel or flaskshaped upper end of the aqueduct is characteristic (Fig. 3). Adhesions at the exit foramina produce an enlarged fourth ventricle (Fig. 4). In congenital atresia a grossly dilated fourth ventricle almost filling the posterior fossa has been described by

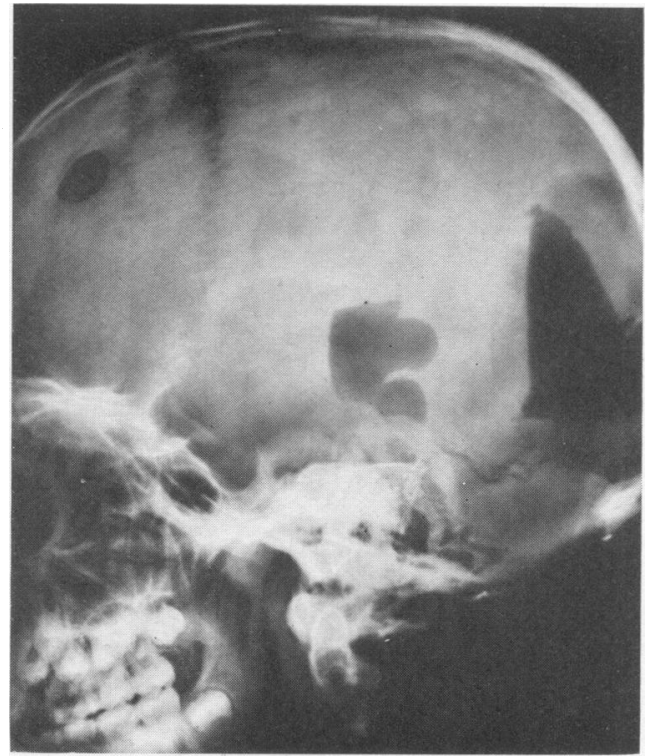

FIG. 3.-The flask-shaped upper end of the aqueduct projects downwards from the posterior end of the dilated third ventricle.

Taggart and Walker (1942), Benda (1954), Maloney (1954) and Gibson (1955). Occurring in foetal life it prevents the caudal migration of the transverse sinuses and torcular Herophili, the impressions of which become moulded on the parietal bones instead of in the usual position on the occipital

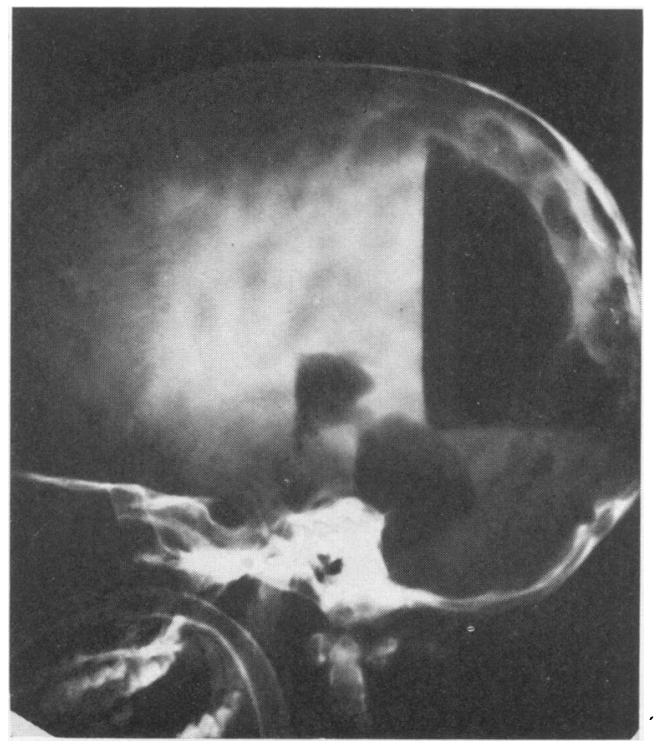

Fig. 4.-Hydrocephalus due to adhesions blocking the foramina of Majendie and Luschka in a child aged 5 years. The fourth ventricle is grossly dilated. 
bone. The radiological appearance of this high lateral sinus was first described by Bucy (1939). These congenital cases may present for the first time in adult life.

The characteristic deformities in the ventriculogram produced by tumours of the cerebellum and brain-stem have been described by Twining (1939b) and Lysholm (1946).

\section{Summary}

The clinical differentiation of obstructive hydrocephalus in childhood is discussed. The cases fall into two main groups-neoplastic and non-neoplastic. In the former the most important conditions are medulloblastoma and astrocytoma of the cerebellum and in the latter stenosis of the aqueduct of Silvius and obliteration of the exit foramina of the fourth ventricle. A differential diagnosis can often be made on clinical grounds with the aid of a plain radiograph of the skull. This may enable the paediatrician to give a more definite prognosis at the first consultation.

We wish to thank the late Mr. C. A. Calvert, F.R.C.S., who had some of the cases in this review under his care, and Mr. D. Mehaffey, A.R.P.S., for the photographs.

REFERENCES

Benda, C. E. (1954). J. Neuropath., 13, 14.

Bucy, P. C. (1939). In Brennemann's Practice of Pediatrics, Vol. 4, Ch. 3, ed. by I. McQuarrie. Hagerstown, Md.

Bull, J. (1953). J. Fac. Radiol. (Lond.), 4, 149.

Davidoff, L. M. and Epstein, B. S. (1950). The Abnormal Pneumoencephalogram. London.

Gibson, J. B. (1955). J. Neuropath., 14, 244.

Lazorthes, G. (1954). Presse med., 62, 906.

Lysholm, E. (1946). Brit. J. Radiol., 19, 437.

Maloney, A. F. J. (1954). J. Neurol. Neurosurg. Psychiat., 17, 134.

Pennybacker, J. (1940). Proc. roy. Soc. Med., 33, 507.

Putnam, T. J. (1934). New Engl. J. Med.. 210, 1373.

Robinson, R. G. (1953). N.Z. med. J., 52, 381

Russell, D. S. (1949). Spec. Rep. Ser., med. Res. Coun. (Lond.), No. 265 .

Taggart, J. K. and Walker, A. E. (1942). Arch. Neurol. Psychiat. (Chicago), 48, 583.

Twining. E. W. (1939a). Brit. J. Radiol., 12, 385.

(1939b). Ibid., 12, 569 . 